UDC 576

LBC 22.311

\title{
PARTICIPATION OF INSULIN-LIKE GROWTH FACTOR 1 IN ARTICULAR CARTILAGE REMODELING
}

\author{
Tatyana S. Ovcharova \\ Volgograd State University, Volgograd, Russian Federation \\ Yuliya A. Zimina \\ Volgograd State University, Volgograd, Russian Federation \\ Pavel A. Krylov \\ Volgograd State University, Volgograd, Russian Federation
}

\begin{abstract}
Upon cartilage damage its natural recovery takes a long time. This is due to several reasons: the absence of blood vessels and low metabolic activity. In this regard, it is relevant to study the mechanism of operation of all components involved in the remodeling of cartilage tissue. For this purpose, protein insulin-like growth factor 1 (IGF-1) was taken as an object of research, since one of its main functions is regulation of cell proliferation, which is closely related to the process of cartilage tissue repair. It is known that in recent years, scientific studies have been conducted on the effect of IGF-1 on the remodeling of cartilage tissues, but in combination with other substances that stimulate more active cell regeneration. This review presents the features of the functional properties and protein structure and its main influence on chondrocyte proliferation for further development of accelerated and effective methods of IGF-1 action on cell growth and repair. The phylogenetic analysis of IGF-1 showed the most related organism for human IGF1 and structural differences of its protein from human, which are inextricably linked with the functional characteristics of each of the organisms. The results of phylogenetic analysis in the future will identify the object for laboratory research in this question and the search for optimal ways to accelerate the process of remodeling of cartilage joints.
\end{abstract}

Key words: insulin growth factor, IGF-1, IFR-1, phylogenetic analysis, chondrocyte, proliferation, cartilage.

Citation. Ovcharova T.S., Zimina Yu.A., Krylov P.A. Participation of Insulin-Like Growth Factor 1 in Articular Cartilage Remodeling. Natural Systems and Resources, 2020, vol. 10, no. 4, pp. 22-29. DOI: https://doi.org/10.15688/ nsr.jvolsu.2020.4.3

\section{УЧАСТИЕ ИНСУЛИНОПОДОБНОГО ФАКТОРА РОСТА 1 В РЕМОДЕЛИРОВАНИИ СУСТАВНОГО ХРЯЩА}

\section{Татьяна Сергеевна Овчарова}

Волгоградский государственный университет, г. Волгоград, Российская Федерация

\section{Юлия Александровна Зимина}

Волгоградский государственный университет, г. Волгоград, Российская Федерация

\section{Павел Андреевич Крылов}

Волгоградский государственный университет, г. Волгоград, Российская Федерация

Аннотация. При повреждении хрящевой ткани ее естественное восстановление занимает длительное время, это связано сразу с несколькими причинами: отсутствием кровеносных сосудов и низкой метаболи- 
ческой активностью. В связи с этим актуальным является изучение механизма работы всех компонентов, участвующих в ремоделировании хрящевой ткани. В качестве объекта исследования был взят белок инсулиноподобный фактор роста 1 (ИГФ-1), так как одна из его основных функций - это регуляция пролиферации клеток, которая тесно связана с процессом восстановления хрящевой ткани. Известно, что в последние годы проводились научные исследования по поводу влияния ИГФ-1 на ремоделирование хрящевой ткани, но уже в совокупности с другими веществами, стимулирующими регенерацию клеток. В данном обзоре представлены особенности структуры и функциональных свойств белка и его ключевого влияния на пролиферацию хондроцитов для дальнейшей разработки ускоренных и эффективных способов действия ИГФ-1 на рост и восстановление клеток. Филогенетический анализ ИГФ-1 показал наиболее родственный организм для ИГФ-1 человека и структурные отличия его белка от человеческого, которые неразрывно связаны с функциональными особенностями каждого из организмов. Результаты филогенетического анализа в дальнейшем позволят выявить объект для лабораторных исследований в данном вопросе и поиске оптимальных способов ускорения процесса ремоделирования хрящевых суставов.

Ключевые слова: инсулиноподобный фактор роста, ИГФ-1, ИФР-1, филогенетический анализ, хондроцит, пролиферация, суставной хрящ.

Цитирование. Овчарова Т. С., Зимина Ю. А., Крылов П. А. Участие инсулиноподобного фактора роста 1 в ремоделировании суставного хряща // Природные системы и ресурсы. - 2020. - Т. 10, № 4. - С. 22-29. DOI: https://doi.org/10.15688/nsr.jvolsu.2020.4.3

\section{Введение}

Инсулиноподобный фактор роста (ИФР-1, IGF-1) представляет собой белок, который влияет на рост всех клеток организма, в том числе и хрящевой ткани. Он участвует на поздней стадии хондрогенеза и стимулирует выработку коллагена II, который увеличивает скорось пролиферации клеток [3]. Кодируется геном, находящимся в 12 хромосоме (рис. 1). Соединение IGF-1 со специфическим рецептором инициирует серию взаимосвязанных процессов, способствующих переводу клеток в активное состояние, накоплению гликогена, стимуляции белкового синтеза, дифференцировке. Посредством связывания ИГФ-1 со связывающим белком 5 (IGFBP5) происходит запуск выработки множества факторов клетки, что в конечном итоге вызывает пролиферацию клеток.

\section{Структура белка}

ИГФ-1 представляет собой одноцепочечный полипептид, состоящий из 6 экзонов (см. рис. 2) [4]. Экзоны 1 и 2 функционально представляют собой сигнальный пептид (48 аминокислот) для посттрансляции клеточной локализации. Они содержат в себе участки инициации транскрипции. Экзоны 3 и 4 главным образом кодируют зрелый пептид IGF-1; в конечном счете, становясь лигандом связывания рецепторов. Экзоны 5 и 6 в основном представляют собой пептид домена Е. Эти части транскрипта дают функциональное различие трем изоформам белка, хотя это еще не до конца изучено. Сращивание экзонов 4 и 6 приводит к последовательности мРНК, которая кодирует 35 аминокислотный Е-пептид, Еа. Его первые 16 аминокислот кодируются экзоном 4, а остальные 19 - экзоном 6 [9]. Еb-пептид происходит от сплайсинга экзона 4 (16 аминокислот) с экзо-

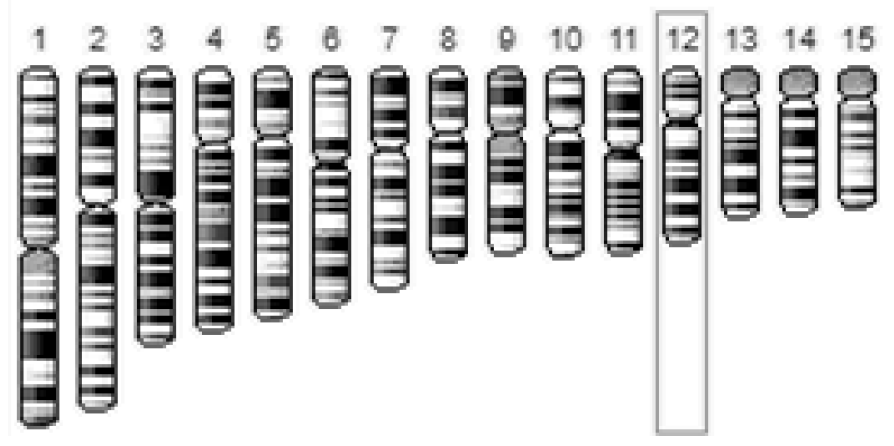

Рис. 1. Расположение гена IGF-1 в геноме человека 


\section{ЭкОЛОГИя И БИОЛОГИЯ}

ном 5 (61 аминокислота). Эта изоформа имеет ядерную и ядрышковую локализацию. Третья изоформа, Ес-пептид, вариант объединения экзонов 4-5-6, содержит 40 аминокислот: 16 из экзона 4,16 из экзона 5 и 8 из экзона $6[2 ; 5]$.

IGF-1 содержит четыре домена: B, C, A, $\mathrm{D}$, которые включают в себя 70 аминокислот и отвечают за апоптоз, миграцию клеток, их пролиферацию и дифференцировку. Домен В играет главную роль, так как несет в себе функцию связывания с IGF-связывающими белками и активацией IGF-1R [8].

\section{Образование}

ИГФ-1 образуется в печени организма под воздействием инсулина и соматотропина, отсюда второе название инсулиноподобного фактора роста - соматомедин С. Этот белок находится в двух состояниях - связанном и несвязанном. Белок-связующим в данном моменте выступает такой белок как IGFBP-3, который уменьшает период полураспада инсулиноподобного фактора роста. В несвязанном состоянии ИГФ-1 активен, но при этом время его существования совсем мало - несколько минут, когда как в связанном все наоборот - белок неактивен, но может успеть транспортироваться по сыворотке крови по всему организму и оказать свое действие, так как время его существования значительно увеличивается до 10-15 часов. Образованию этого связующего белка способствует гормон роста соматотропин.

\section{Функции}

ИГФ-1 в больших концентрациях может вызвать активацию рецепторов инсулина и дополнять его действие. Но рецепторы, отвечающие за сигналы одного, могут локализоваться там, где другое вещество не встречается. ИГФ-1 также участвует в развитии плода, принимая активное участие в стимуляции пролиферации клеток всех тканей, в первую очередь - хрящевой и костной. Выявлена прямая зависимость между концентрацией ИГФ1 и содержанием остеокальцина в сыворотке крови, являющегося показателем интенсивности костного ремоделирования, которое связано с хрящевым. Также белок продолжает являться ключевым белком для гомеостаза суставного хряща в течение всей жизни человека и оказывает свое влияние на поздние стадии хондрогенеза [10]. ИГФ-1 стимулирует выработку коллагена II типа и основного белка матрицы, что приводит к увеличению скорости пролиферации клеток. Уровень белка при активной мышечной деятельности сильно повышается после физической нагрузки или травмы.

\section{Влияние ИГФ-1 на хрящевые суставы в совокупности с другими веществами}

Как вариант анаболического средства можно рассмотреть кленбутерол, обладающий необходимыми свойствами. Подобно ИГФ-1 он стимулирует рост хрящевой ткани, и оба вещества будут участвовать в восстановлении суставов после травм. А вот повышение уровня тестостерона в крови влияло на стимуляцию усиленной работы печени, которая увеличила дозу выделения исследуемого белка.

Адреналин в малых количествах будет влиять на организм, как и лучевая или

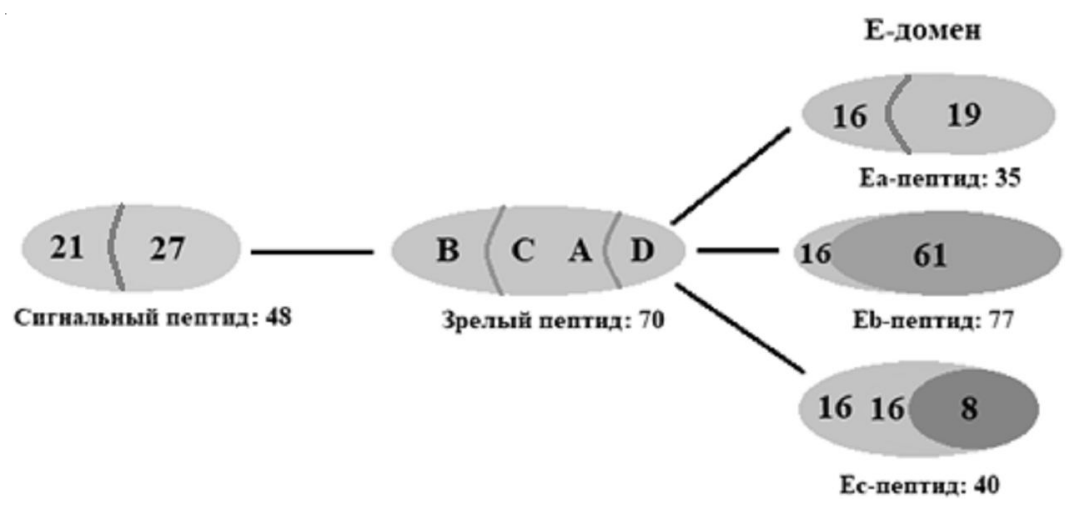

Рис. 2. Пептидное строение ИГФ-1 
магнитная терапия - расширять сосуды, повышая давление. Тем самым ИГФ-1 будет быстрее начинать действовать на хрящевой сустав.

Одновременное использование двух факторов роста ИГФ-1 и ИГФ-2 может привести также к стимуляции более активной регенерации хрящевой ткани. Данные показывают, что комбинированная сверхэкспрессия обоих веществ в дефектах суставного хряща с помощью встроенных в альгинат клеток NIH 3 T3 значительно усиливают восстановление дефектов остеохондрального хряща на всю толщину после 3 недель in vivo на величину, большую, чем при использовании одного ИГФ-1.

Однако наиболее высокую эффективность в работе с ИГФ-1 показал именно соматотропный гормон (СТГ). Он оказывает гораздо большее влияние на рост хрящей, чем тестостерон или инсулин, но особенно больший эффект можно достичь, используя его вместе с тиреокальцитонином - особым белком гормона щитовидной железы, который усиливает репарацию как костной, так и хрящевой ткани [6]. СТГ влияет на деление хондроцитов, которые в свою очередь начинают секретировать матрикс, тем самым синтезируя все его необходимые компоненты и ускоряя процесс заживления.

В отдельности использовать ИГФ-1 можно, но процесс восстановления тогда будет очень долгим и не сможет дать более укрепленного результата. СТГ нужен не только для того, чтобы оказывать стимулирующее влияние на хондроциты, но и влиять на печень, которая будет производить белок связующий IGFBP-3. Он увеличивает время до полураспада инсулиноподобного фактора роста, чтобы тот успел в полной мере подействовать на травматическое место.

\section{Ингибирование}

Рецепторы тирозинкиназы, включая рецептор ИГФ-1 типа I (IGF-1R), опосредуют активность белков, вызывая добавление фосфатных групп к определенным тирозинам на определенных белках в клетке. IGF-1R фосфорилирован, его киназный домен может служить местом стыковки для нескольких бел- ков, включая белки субстрата рецептора инсулина (IRS) и белки Src гомологии/коллагена (Shc) [7]. Эти два субстрата служат посредниками и стыковочными узлами для распространения «нисходящей клеточной сигнализации», и обычным результатом активации рецептора ИГФ-1 является пролиферация в компетентных к митозу клетках, в том числе и хрящевых, а также гипертрофия в тканях, таких как скелетные мышцы и сердечная мышца.

\section{Участие IGF-1 в пролиферации клеток}

Связанный с IGFBP5 инсулиноподобный фактор роста I является лигандом рецептора IGF-1R, который относится к семейству тирозинкиназ. Рецептор состоит из двух субъединиц: $\alpha$ и $\beta$ [10]. Связываясь с экстрацеллюлярной $\alpha$-субъединицей, происходит активация В домена белка и киназного домена рецептора, что приводит к активации процесса фосфорилирования тирозиновых остатков при попадании в $\beta$-субъединицу. Внутри нее находится консервативный элемент, богатый глицином, который участвует в переносе фосфатной части АТФ на определенные субстраты, такие как Shc и IRS. Происходит активация основного сигнального пути посредством Ras, который ведет к стимуляции клеточной пролиферации. Shc связывает активированные рецепторные тирозинкиназы с Ras, белками, участвующими в передаче сигнала в клетке. Далее Ras взаимодействует с факторами Grb2/SOS - рецептор-связующий белок 2 , участвующий в передаче сигнала посредством домена $\mathrm{SH} 2$, который связывает фосфорилированные последовательности тирозина/фактор обмена нуклеотидов гуанина. Активированный Ras стимулирует протеинкиназную активность RAF киназы, которая фосфорилирует и активирует МЕК, а также MAРК, митоген-активируемую протеинкиназу, которая влияет на активацию транскрипционного фактора Erk. В совокупности с MEK Erk обеспечивает механизм преобразования воздействия ИГФ-1 на клетку в изменении экспрессии генов, который лежит в основе влияния ИГФ на пролиферацию (см. рис. 3) [1]. 


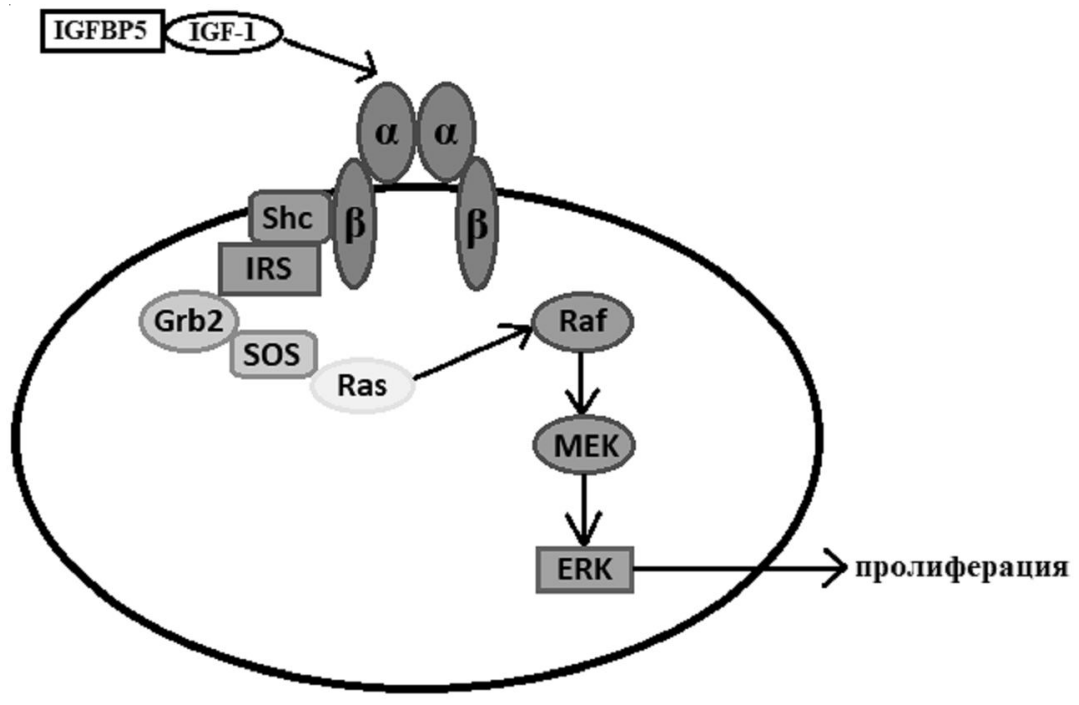

Рис. 3. ИФР-опосредованный сигнальный путь:

IGF-1R - ИФР-рецептор I типа семейства тирозинкиназ; IGF-1 - инсулиноподобный фактор роста; IGFBs - протеины, связывающие ИФР и регулирующие их биодоступность; IRS - внутриклеточные субстраты инсулинового рецептора;

Ras, Raf, MEK и ERK - компоненты митоген-активируемого протеинкиназного сигнального пути [1]

\section{Материалы и методы}

Филогенетический анализ осуществлялся проводился путем посредством построения эволюционных деревьев с помощью программы MEGA-X (Pennsylvania State University, USA) который позволял найти различия между организмами и выявить наиболее схожий с человеческим ИГФ-1. В качестве основных организмов были выбраны млекопитающие: домовая мышь (Mus Musculus), серая крыса (Rattus norvegicus), корова (Bos Taurus), домашняя свинья (Sus scrofa), домашняя овца (Ovis aries). Данные для построение филогенетических деревьев были сохранены в формате FASTA полученные из базы данных UniProt и впоследствии загружены в программy ClustlW для проведения множественного выравнивания. Для построения филогенетического дерева по IGF-1 использовался метод максимального правдоподобия (MaximumLikelihood) на основе матричной модели JonesTaylor-Thornton (JTT), с помощью которого можно узнать уровень дифференцировки белков в процессе эволюции. Дерево построено в масштабе с длиной ветвей, измеренной числом замен на сайт. Результаты множественного выравнивания помогут определить, в каких структурных элементах ИГФ-1 будет заметно отличие в аминокислотных последова- тельностях и как это связано с функциональными особенностями.

\section{Результаты}

По окончании построения филогенетического дерева можно заметить, что наиболее родственным организмом для ИГФ-1 человека считается домашняя мышь. При множественном выравнивании было отмечено их сходство, поэтому для проведения экспериментов наиболее подходящим организмом будет являться именно мышь (см. рис. 4).

При множественном выравнивании наибольшие отличия замечались в самом начале цепочек, в районе первого доменного участка В. Таким образом, в процессе эволюции наибольшему изменению подвергся именно данный домен. Он отвечает за функцию связывания с IGF-связывающими белками и активацией IGF-1R, а также является ключевым белком для гомеостаза суставного хряща. Так как в процессе эволюции строение организмов усложнялось, в том числе и костная система, то видоизменялось и строение белка, отвечающего за пролиферацию и тем самым развитие костной и хрящевой ткани организма.

Также стоит отметить наиболее длинную цепочку у человеческого белка - последнего домена Е, основными функциями которого 


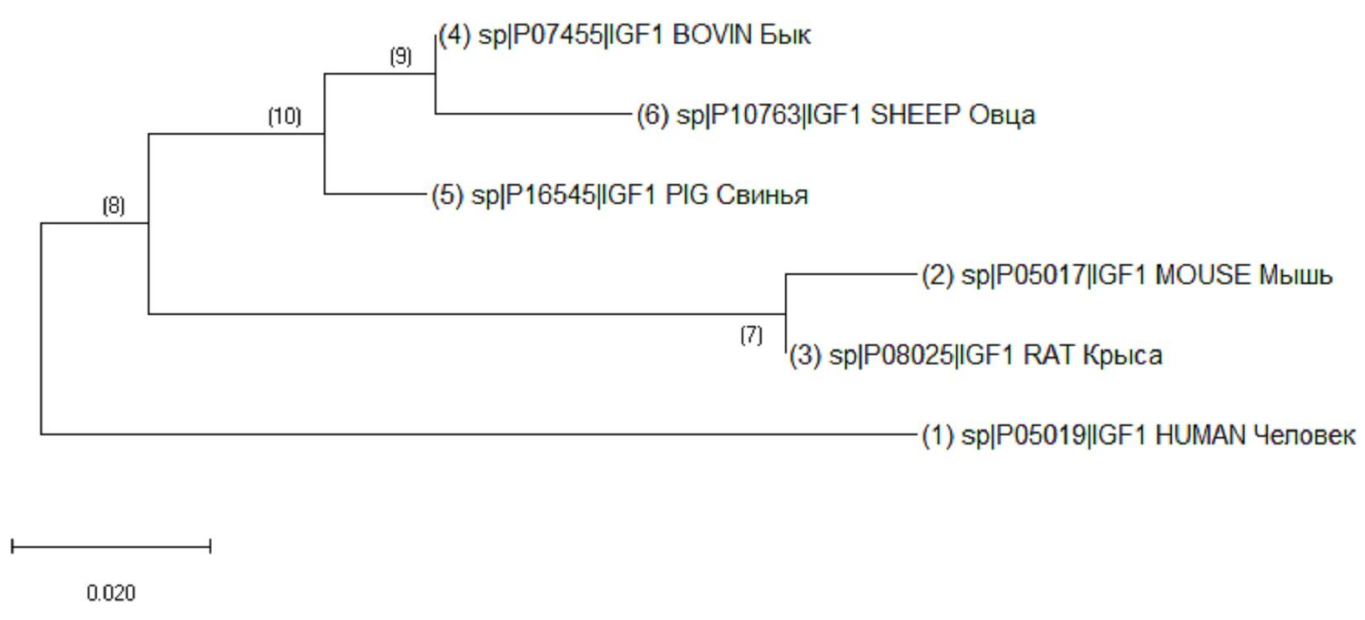

Рис. 4. Филогенетический анализ по методу Maximum-Likelihood

является активация сателлитных клеток, которые могут пролиферировать зрелый ИГФ-1 и изоформу пептида-Ес, что поддерживает повышенный уровень механического фактора роста - разновидность ИГФ, который ускоряет процесс регенерации клеток. Различия в последнем домене влияют на скорость восстановления клеток, ведь известно, что Еспептид на 73 \% гомологичен Еb-пептиду мыши, который у грызунов отвечает за усиление пролиферации клеток.

\section{Заключение}

Инсулиноподобный фактор роста 1 играет одну из важных ролей в пролиферации клеток, и особенности его действия могут помочь науке в разработке препаратов или способов по ускорению восстановления поврежденных тканей. Так, домен В ИГФ-1, связываясь с IGFBP5, взаимодействует с рецептором. В итоге белок принимает активное участие в процессе дифференциации позвонков, активируя ряд соединений внутри самих клеток, которые и запускают процесс роста клеток. Сейчас проводятся исследования по поиску методов ускорения восстановления поврежденных суставных хрящей с помощью ИГФ-1 в чистом виде и в комплексе с другими соединениями. И для этого в качестве лабораторных образцов можно использовать домашних мышей, так как эволюционно человеческий и мышиный белок разнятся минимально. Отличия заключаются в различных последовательностях аминокислот в доменах В и Е, которые ответствен- ны за связывание белка и усиление пролиферации клеток.

\section{СПИСОК ЛИТЕРАТУРЫ}

1. Бочкарева, И. В. Инсулиноподобные факторы роста и связывающие их белки в патогенезе рака эндометрия / И. В. Бочкарева, И. В. Кондакова, Л. А. Коломиец // Сибирский онкологический журнал. - 2008. - Vol. 27, № 3. - C. 86-93.

2. An alternatively spliced human insulin-like growth factor-I transcript with hepatic tissue expression that diverts away from the mitogenic IBE1 peptide / S.L. Chew [et al.] // Endocrinology. - 1995. Vol. 136, № 5 - P. 1939-1944. - DOI: https://doi.org/ 10.1210/endo.136.5.7720641.

3. Cartilage repair: past and future-lessons for regenerative medicine / G. van Osch [et al.] // CellMol. 2009. - Vol. 13, № 5. - P. 792-810. - DOI: https://doi.org/ 10.1111/j.1582-4934.2009.00789.x.

4. Jones, J. I. Insulin-like growth factors and their binding proteins: biological actions / J. I. Jones, D. R. Clemmons // Endocrine Reviews. - 1995. - Vol. 16, № 1.-P. 3-34. - DOI: https://doi.org/10.1210/edrv-16-1-3.

5. LeRoith, D. Molecular and cellular aspects of the insulin-like growth factor I receptor / D. LeRoith, H. Werner, D. Beitner-Johnson / Endocrine Reviews. 1995. - Vol. 16, № 2. - P. 143-163. - DOI: https://doi.org/ 10.1210/edrv-16-2-143.

6. Receptors for insulin-like growth factor-I in plasma membranes isolated from bovine mesenteric arteries / K.E. Bornfeldt [et al.] // Acta Endocrinol. 1988. - Vol. 117, № 4. - P. 428-34. - DOI: https://doi.org/ 10.1530/acta.0.1170428

7. Specificity in ligand binding and intracellular signalling by insulin and insulin-like growth factor receptors / K. Siddle [et al.] // Biochemical Society 
Transaction. - 2001. - Vol. 29, № 4. - P. 513-525. DOI: https://doi.org/10.1042/bst0290513.

8. Structural basis for the lower affinity of the insulin-like growth factors for the insulin receptor / L. Gauguin [et al.] // The Journal of Biological Chemistry. - 2008. - Vol. 283, № 5. - P. 2604-2613. DOI: https://doi.org/10.1074/jbc.m709220200.

9. The role of the insulin-like growth factor 1 (IGF-1) in skeletal muscle physiology / A. Philippou [et al.] // In Vivo. - 2007. - Vol. 21, № 1. - P. 45-54.

10. Zhang, H. Is the type I insulin-like growth factor receptor a therapeutic target in endometrial cancer? / H. Zhang, D. Yee // Clinical Cancer Research. - 2006. - Vol. 12. № 21. - P. 6323-6325. DOI: https://doi.org/10.1158/1078-0432.

\section{REFERENCES}

1. Bochkareva I.V., Kondakova I.V., Kolomiets L.A. Insulinopodobnye faktory rosta $\mathrm{i}$ sviazyvaiushchie ikh belki v patogeneze raka endometriia [Insulin-like growth factors and their binding proteins in the pathogenesis of endometrial cancer]. Siberian journal of Oncology, 2008, vol. 27, no. 3, pp. 86-93.

2. Chew S.L., Lavender P., Clark A.J. et al. An alternatively spliced human insulin-like growth factor-I transcript with hepatic tissue expression that diverts away from the mitogenic IBE1 peptide. Endocrinology, 1995, vol. 136, no. 5, pp. 1939-1944. DOI: https://doi.org/10.1210/endo.136.5.7720641.

3. van Osch G., Brittberg M., Dennis J.E. et al. Cartilage repair: past and future-lessons for regenerative medicine. CellMol, 2009, vol. 13, no. 5, pp. 792-810. DOI: https://doi.org/10.1111/j.15824934.2009.00789.x.

4. Jones J.I., Clemmons D.R. Insulin-like growth factors and their binding proteins: biological actions. Endocrine Reviews, 1995, vol. 16, no. 1, pp. 3-34. DOI: https://doi.org/10.1210/edrv-16-1-3.

5. LeRoith D., Werner H., Beitner-Johnson D. Molecular and cellular aspects of the insulin-like growth factor I receptor. Endocrine Reviews, 1995, vol. 16, no. 2, pp. 143-163. DOI: https://doi.org/10.1210/ edrv-16-2-143.

6. Bornfeldt K.E., Arnqvist H.J., Dahlkvist H.H. et al. Receptors for insulin-like growth factor-I in plasma membranes isolated from bovine mesenteric arteries. Acta Endocrinol, 1988, vol. 117, no. 4, pp. 428-34. DOI: https://doi.org/10.1530/acta.0.1170428.

7. Siddle K., Urso B., Niesler C.A. et al. Specificity in ligand binding and intracellular signalling by insulin and insulin-like growth factor receptors. Biochemical Society Transaction, 2001, vol. 29, no. 4, pp. 513-525. DOI: https://doi.org/10.1042/bst0290513

8. Gauguin L., Klaproth B., Sajid W. et al. Structural basis for the lower affinity of the insulinlike growth factors for the insulin receptor. The Journal of Biological Chemistry, 2008, vol. 283, no. 5, pp. 26042613. DOI: https://doi.org/10.1074/jbc.m709220200.

9. Philippou A., Maridaki M., Halapas A. et al. The role of the insulin-like growth factor 1 (IGF-1) in skeletal muscle physiology. In Vivo, 2007, vol. 21, no. 1, pp. 45-54.

10. Zhang H., Yee D. Is the type I insulin-like growth factor receptor a therapeutic target in endometrial cancer? Clinical Cancer Research, 2006, vol. 12, no. 21, pp. 6323-6325. DOI: https://doi.org/ $10.1158 / 1078-0432$.

\section{Information About the Authors}

Tatyana S. Ovcharova, Student, Department of Bioengineering and Bioinformatics, Volgograd State University, Prosp. Universitetsky, 100, 400062 Volgograd, Russian Federation, tatyanka.ovcharova.00@mail.ru

Yuliya A. Zimina, Candidate of Sciences (Chemistry), Associate Professor, Department of Bioengineering and Bioinformatics, Volgograd State University, Prosp. Universitetsky, 100, 400062 Volgograd, Russian Federation, zimina.yuliya@volsu.ru

Pavel A. Krylov, Candidate of Sciences (Biology), Associate Professor, Department of Bioengineering and Bioinformatics, Volgograd State University, Prosp. Universitetsky, 100, 400062 Volgograd, Russian Federation, krylov.pavel@volsu.ru

\section{Информация об авторах}

Татьяна Сергеевна Овчарова, студент кафедры биоинженерии и биоинформатики, Волгоградский государственный университет, просп. Университетский, 100, 400062 г. Волгоград, Российская Федерация, tatyanka.ovcharova.00@mail.ru 
Зимина Юлия Александровна, кандидат химических наук, доцент кафедры биоинженерии и биоинформатики, Волгоградский государственный университет, просп. Университетский, 100, 400062 г. Волгоград, Российская Федерация, zimina.yuliya@volsu.ru

Павел Андреевич Крылов, кандидат биологических наук, доцент кафедры биоинженерии и биоинформатики, Волгоградский государственный университет, просп. Университетский, 100, 400062 г. Волгоград, Российская Федерация, krylov.pavel@volsu.ru 